\title{
A COMPARATIVE STUDY OF INTONATION CHARACTERISTICS OF SPEECHES BY CHINESE EFL LEARNERS AND NATIVE SPEAKERS
}

\author{
Yunjie Huang 1 , Yi Zhang ${ }^{*}$ 伲 \\ $1,{ }^{* 2}$ School of Foreign Studies, Northwestern Polytechnical University, China
}

DOI: https://doi.org/10.29121/granthaalayah.v8.i11.2020.2438

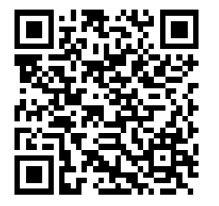

Article Type: Research Article

Article Citation: Yunjie Huang and Yi Zhang. (2020). A COMPARATIVE STUDY OF INTONATION

CHARACTERISTICS OF SPEECHES BY CHINESE EFL LEARNERS AND

NATIVE SPEAKERS. International Journal of Research -

GRANTHAALAYAH, 8(11), 195-203. https://doi.org/10.29121/granthaa layah.v8.i11.2020.2438

Received Date: 10 November 2020

Accepted Date: 30 November 2020

Keywords:

Intonation

Speech

Efl Learner

\begin{abstract}
Intonation plays an essential role in verbal communication. Besides, intonation patterns that influence information transmission in speeches have always been a significant research focus in current years. Based on Halliday's intonation systems, this study investigated the intonation features, including tonality, tonicity and tone shown in speeches of Chinese EFL learners and English native speakers. In the study, the acoustic tool Praat and Excel were employed to label the data and analyze the obtained statistics. Results indicated that Chinese students were able to use tone groups and marked tonicity to emphasize the focus of information units. However, there existed some improper and excessive use of tonality segmentation and marked tonicity. Moreover, Chinese students showed more changeable tones when delivering speeches, which might create an understanding barrier of listeners. In order to improve Chinese EFL learners' use of intonation, a more thorough comprehension of the information units, key focus and meaning of each tone is required.
\end{abstract}

\section{INTRODUCTION}

Intonation is the change of pitch of the whole utterance and is the pattern of pitch movement. It is also a means of expression, and one of its most essential functions is an emotional function (Zhang, Chao, Huang et al., 2020). Besides, intonation also has a specific function of semantic expression. The function of intonation can be divided into two dimensions, including emotional and semantic facets. The emotional function includes indicating statement, question, imperative and exclamation, while semantic intonation generally expresses happiness, fear, sadness or disgust (Cao, 2002). Therefore, as one of the important means to carry information in oral English communication, mastering and using intonation properly and correctly should be regarded as a significant and necessary goal (Yang, 2020). Currently, those intonational studies about expression and communication mainly focused on intonational studying and education (Zou, 2020; Yang, 2020); intonational perception and therapy (Han, Zhang \& Xiao, 2020; He, Yang et al., 2020; Steffman, 2019); or the epistemic meanings realized by intonation (Honnet, Grazov et al., 2018; O'Grady, 2020). However, to our knowledge, there were limited studies that paid much attention to the function of intonation in presenting speeches, although intonation played exactly an important role in transmitting oral information (Chen, 2008). One of the useful methods for improving the teaching and education of English intonation

(C) 2020 The Author(s). This is an open access article distributed under the terms of the Creative Commons Attribution License, which permits unrestricted use, distribution, and reproduction in any medium, provided the original author and source are credited. 
is to make a comparison of the intonation between the learners and native speakers. Through finding out the difference, the incorrect or improper use of English intonation by Chinese students can be found and summarized. Thus, this study probed into the intonational characteristics of speeches by Chinese English as foreign language learners (EFL), which were compared with that of English native speakers. Under the framework of Halliday's intonation systems (1967), the tonality segmentation, the use of marked tonicity and distinctive tones that speakers used in speeches were investigated. Through the comparison of intonation features, this research hopes to provide some suggestions for the intonation teaching and improvement of Chinese EFL learners. Three questions guided the exploration of the present studies.

1) What are the features of the tonality segmentation of the two groups of speakers?

2) What are the features of the tonicity employed by two groups of speakers?

3) What is the frequency of different tones that were used by two groups of speakers?

\subsection{DEFINITIONS OF INTONATION}

With regard to the definitions of intonation, a kind of suprasegmental phenomena with pitch movement as the main characteristics in human language (Chen \& Bi, 2015; Chen, 2009), there existed the broad and narrow descriptions. Broadly speaking, intonation involved pitch, intensity, speech length, pause, stress, rhythm and some relevant suprasegmental events (Allen, 1971; Cruttenden, 2002; Halliday, 1967; Ladd, 1996; Tench, 1996). However, in a narrow sense, pitch rising and falling from the aspect of the acoustic, phonetic and phonological level were investigated and considered (Chen, 2009). Based on the broad definition, intonation could be employed to indicate the grammatical boundaries and the syntactic structure of the utterance. Moreover, the information focus could be transmitted by the prominent part within an intonation contour (Crystal, 1969; 1975; Halliday, 1967).

\subsection{HALLIDAY'S 3-T THEORY}

The intonation system encompassed three different systems, including the tonality, the tonicity and the tone (Halliday, 1967). From the perspective of intonation systems, tonality could split the utterance into several tone groups. These tone groups were the basic components of English intonation. Tonicity played the core role in one tone group and represented the information focus of that information unit as well. There were two kinds of tonicity, of which one was the marked tonicity, and another one was the unmarked tonicity. Most of the tonicity was located at the last lexical item of the tone group and was called as unmarked tonicity (Crystal, 1975). However, when the speaker needed to emphasize some specific information, the information focus might be put on the items other than the last lexical item within one tone unit. At this time, this kind of tonicity was regarded as the marked tonicity. When there was no special purpose of expression or explanation, using the unmarked tonicity was the relatively best choice (Halliday \& Greaves, 2008). Another part of the intonation system was the tone, which could be described as the pitch trajectory on the tonicity. As stated by Halliday (2008), five distinctive tones (Tone 1, Tone 2, Tone 3, Tone 4 and Tone 5) composed of the primary tone system and two further kinds of intonation contour (Tone 13 and Tone 53).

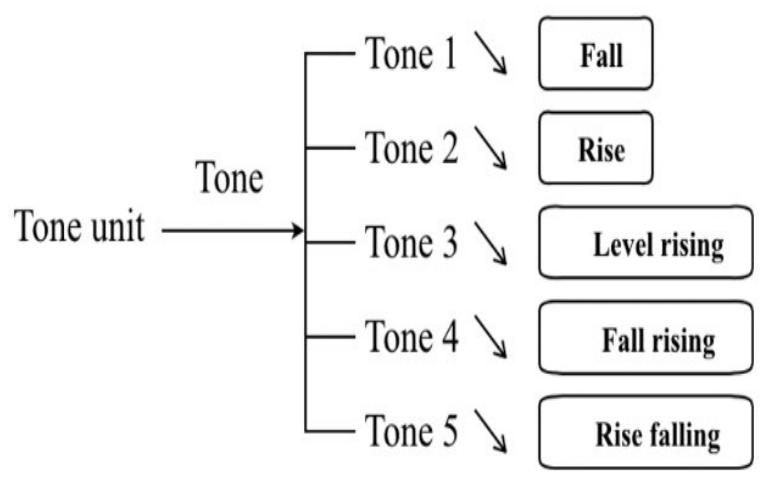

Figure 1: Illustration of the simple tones (Halliday \& Greaves, 2008) 


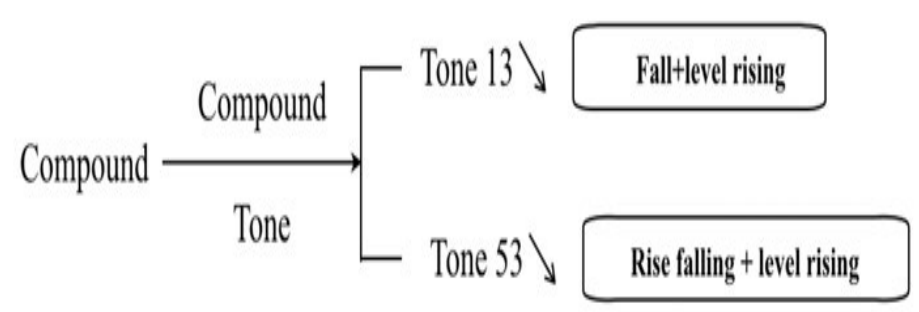

Figure 2: Illustration of the compound tones (Halliday \& Greaves, 2008)

This study used Halliday's intonation system as the theoretical framework and regarded the tonality, the tonicity and the tone as three research focuses.

\section{MATERIALS AND METHODS}

\subsection{RESEARCH SUBJECTS AND DESCRIPTION OF THE CORPUS}

English native speakers and Chinese EFL learners were the research subjects of the study. Their speeches were used as the research samples and for the comparison. Specifically, graduation speeches that five famous people delivered in the United States and the speeches presented by 17 Chinese students at $21^{\text {st }}$ Century Coca-Cola Cup National English Contest were used as the corpus.

\begin{tabular}{cccc}
\hline Corpus & Corpus source & Total duration & Topics of speeches \\
\hline English native & Graduation speeches from & & Study, \\
speakers & famous universities in the & $71 \mathrm{~m} 12 \mathrm{~s}$ & $\begin{array}{c}\text { globalization, } \\
\text { equality, dream, }\end{array}$ \\
(ENSC) & United States & & culture, dream, \\
Chinese EFL & Final speeches of the $21^{\text {st }}$ & & future \\
learners & Century Coca-Cola Cup & $71 \mathrm{~m} 32 \mathrm{~s}$ & \\
$($ CELC) & National English Contest & & \\
\hline
\end{tabular}

Figure 3: Description of the research corpus

By reason of the significant distinction of the length of a single speech (for instance, 3 minutes for the single speech delivered by NNES but 15 minutes for the single speech presented by NES) by the two groups of speakers, the study tried to control the total duration, the number of words and topics of the two corpora. Moreover, in order to control the influence of syntactic structures, merely complex and simple sentences were selected for the final investigation.

\subsection{RESEARCH INSTRUMENT AND DATA PROCESSING}

\subsubsection{TOOLS FOR PROCESSING SOUNDS}

Audacity for Mac was employed for editing the original speech from two spoken corpora and eliminating the noise of speeches. 


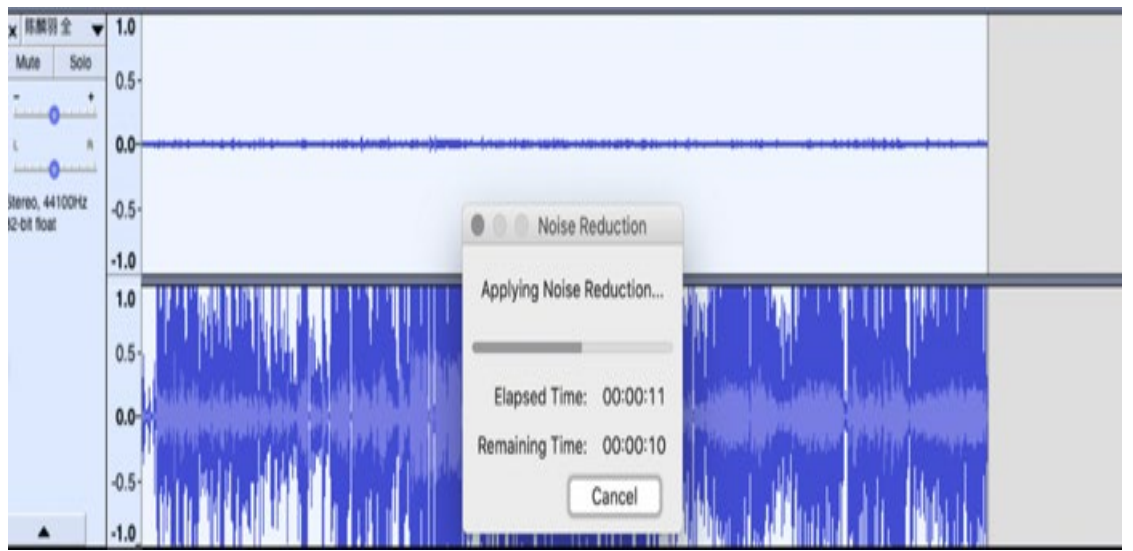

Figure 4: Example of the use of Audacity for Mac

As a cross-platform, multi-functional acoustic software, Praat was mainly used for processing and analyzing the audio files in the present study. In details, the pitch curve, fundamental frequency, sound amplitude were investigated and analyzed through Praat. Besides, this tool was also employed for labelling the speech sound with reference to Halliday's (1967) intonation systems.

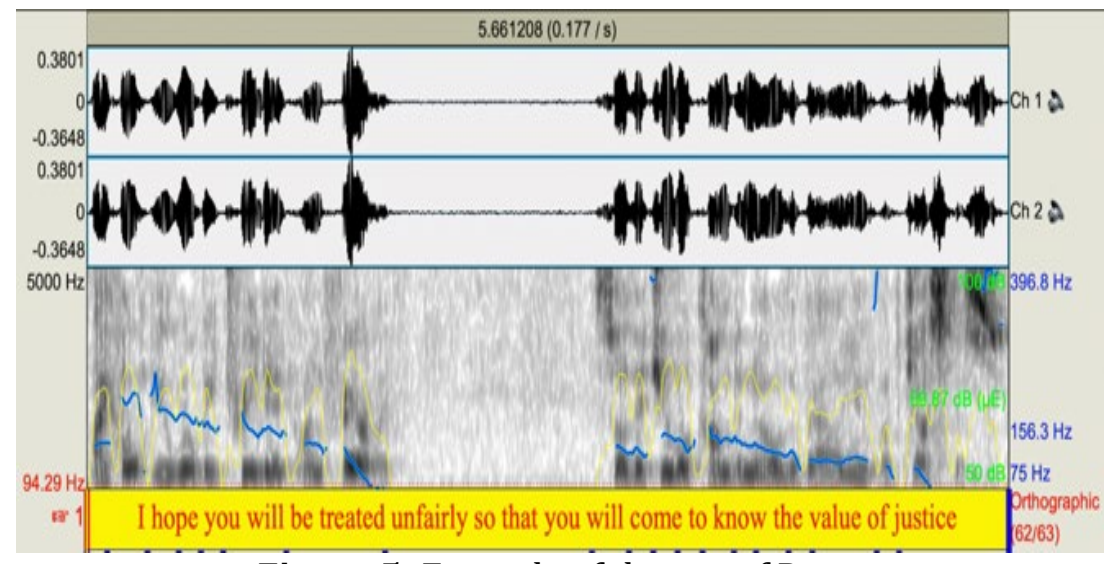

Figure 5: Example of the use of Praat

\subsubsection{TOOLS FOR CALCULATING AND RECORDING STATISTICS}

Pages is a powerful word processor that can be used to create stunning documents. In this study, Pages was firstly used for marking the syntactic structures (complex and simple sentences) of speeches. Then the tool was employed to label the intonation of speeches. Another tool that the study used to analyze the statistics was IBM SPSS. It was used to do the descriptive analysis, calculating the mean value of the frequency, and some relevant information.

\subsubsection{DATA LABELLING}

Halliday's tone system (1967) was the basis of the labelling process. T1, T2, T3, T4, T5, T13 and T53 were used to mark different tones that speakers used in speeches. When processing the sound file, the words of the utterance were first recorded. After that, the tones of each tone group were labelled under the framework of the tone system.

Table 1: Description of tones

\begin{tabular}{|c|c|}
\hline Tone & Description \\
\hline Tone 1 & Fall \\
\hline Tone 2 & Rise \\
\hline Tone 3 & Level rising \\
\hline
\end{tabular}


Yunjie Huang, Yi Zhang

\begin{tabular}{|c|c|}
\hline Tone 4 & Fall rising \\
\hline Tone 5 & Rise falling \\
\hline Tone 13 & Fall + level rising \\
\hline Tone 53 & Rise falling + level rising \\
\hline
\end{tabular}

\section{RESULTS AND DISCUSSIONS}

In order to compare the features of using tonality segmentation by the two groups of speakers, statistics including mean, sum and distribution were analyzed and presented.

Table 2 listed below shows the frequency of using the tonality by English native speakers (NES) and non-native English speakers (NNES) in both simple and complex sentences.

Table 2: Comparison of the tonality segmentation by the two groups of speakers

\begin{tabular}{|l|l|l|l|l|}
\hline & Simple & Complex \\
\cline { 2 - 5 } & NNES & NES & NNES & NES \\
\hline Mean & 47 & 26 & 68 & 63 \\
\hline Sum & 796 & 427 & 1160 & 1072 \\
\hline Distribution & 3 & 1.2 & 5.5 & 4.4 \\
\hline
\end{tabular}

(Note: Distribution=Number of tonality / Number of complex sentences)

In simple sentences, NNES (mean=47>mean=26; sum=796>sum=427) used more tonality segmentation than NES. Besides, the difference between the distribution of the use of tonality segmentation (NNES=3; NES=1.2) indicated that Chinese EFL learners were more likely to use several tone groups in one simple sentence. But English native speakers preferred to use one tone group when there was a single simple sentence. When it came to complex sentences, there was no significant difference in the use of tonality segmentation of NNES and NES. Nevertheless, Chinese EFL learners divided the sentences more frequently (distribution: NNES=5.5>NES $=4.4$ ) than native English speakers.

For the sake of illustrating the distinction of the use of tonality segmentation, two examples were listed here.

Example:

1) //Now / I've / given / a / lot of / speeches / about / education // (NES-2)

2) // Have / you // ever // bought / any / food // on / the / train // And // do / you / ask // for / the / receipt // after / buying / it // (NNES-3)

Examples listed above show the use of tone groups in several simple sentences by native English speakers and Chinese EFL learners. In Example 1), NES-2 used merely one tone groups when uttering this simple sentence. However, as for Example 2), Chinese students used more than one tone group when presenting simple sentences. The excessive employment of tonality segmentation in simple sentences probably caused the understanding barrier of listeners.

Based on the description of statistics and the explanation of examples listed above, it could draw an inference that Chinese students could consciously use tone groups to divide the sentence into several information units. However, improper or excessive use of tonality segmentation might cause the barrier of listeners' understanding.

\subsection{TONICITY OF NATIVE ENGLISH SPEAKERS AND CHINESE EFL LEARNERS}

When focusing on the tonicity used by the two groups of speakers, two distinctive facets were considered. The first one is the frequency of using marked tonicity, which was represented by the number of times the marked tonicity was employed in the speech. The second one is the location, which was mainly reflected by the part of speech of the items. 
A Comparative Study of Intonation Characteristics of Speeches by Chinese Efl Learners and Native Speakers

Table 3 below presented the frequency of marked tonicity that NES and NNES used in their speeches.

Table 3: Comparison of the frequency of marked tonicity

\begin{tabular}{|l|l|l|l|l|}
\hline & \multicolumn{2}{|c|}{ Simple } & \multicolumn{2}{c|}{ Complex } \\
\cline { 2 - 5 } & NNES & NES & NNES & NES \\
\hline Mean & 23 & 14 & 34.2 & 28.9 \\
\hline Sum & 391 & 248 & 582 & 491 \\
\hline Distribution $^{1}$ & 1.5 & 1 & 2.2 & 2.1 \\
\hline Distribution $^{2}$ & $5.80 \%$ & $5.60 \%$ & $50.20 \%$ & $45.90 \%$ \\
\hline
\end{tabular}

(Notes: Distribution ${ }^{1}=$ Number of marked tonicity / Number of simple sentences;

Distribution $^{2}=$ Mean of number of marked tonicity / Mean of number of tone groups)

On the whole, in both simple and complex sentences, NNES were more likely to use marked tonicity than NES. No matter the mean or the sum did show the significant difference of using the marked tonicity. In complex sentences, there existed a more obvious difference in the statistics, especially in the comparison of distribution ${ }^{2}$. Chinese EFL learners (distribution ${ }^{2}=50.2 \%$ ) presented a higher distribution of using marked tonicity than native English speakers (distribution ${ }^{2}=45.9 \%$ ).

Table 4: Comparison of the location of marked tonicity

\begin{tabular}{|c|c|c|c|c|c|c|}
\hline Sentence types & Speakers & Conjunction & Preposition & Determiner & Article & Content word \\
\hline \multirow{2}{*}{ Simple } & NNES & $2(0.00 \%)$ & $9(2.30 \%)$ & $2(0.00 \%)$ & $2(0.00 \%)$ & $376(96.20 \%)$ \\
\cline { 2 - 7 } & NES & $0(0.00 \%)$ & $2(0.00 \%)$ & $2(0.00 \%)$ & $0(0.00 \%)$ & $244(98.40 \%)$ \\
\hline \multirow{2}{*}{ Complex } & NNES & $2(0.00 \%)$ & $21(3.61 \%)$ & $3(0.00 \%)$ & $4(0.00 \%)$ & $552(94.85 \%)$ \\
\cline { 2 - 7 } & NES & $4(0.00 \%)$ & $3(0.00 \%)$ & $2(0.00 \%)$ & $1(0.00 \%)$ & $481(97.96 \%)$ \\
\hline
\end{tabular}

Table 4 shows the parts of speech of marked tonicity that the Chinese students and English native speakers used in their speeches. Several parts of speech including conjunction, determiner, article, proposition and some other content words were employed when using the marked tonicity. Due to the discussion of the present study mainly concentrated on the correctness of the employment of marked tonicity, the key information involving nouns, verbs, adverbs were generalized as the content word here. From Table 4, both NES (simple=98.40\%; complex=97.96\%) and NNES (simple=96.20\%; complex=94.85\%) used marked tonicity most frequently when they spoke content words no matter in simple or complex sentences. However, there still existed some slight difference in the use of the preposition. Chinese EFL learners (simple $=2.3 \%$; complex $=3.61 \%$ ) used much more preposition than native English speakers $($ simple $=$ complex $=0 \%)$ in speeches.

Example:

3) //You've reached an important milestone // (NES-1)

4) // That / was / almost/100/years / ago // (NNES-4)

In Example 3) and Example 4), the use of marked tonicity of English native speakers and Chinese EFL learners are presented. Regarding the word "important" accentuated by NES-1, the speaker consciously put the information focus on the adjective instead of the noun at the end of the utterance. The main purpose of this kind of use might be to let listeners notice the importance of the current stage they were in (The audiences of the speech that NES-1 gave were senior students at the junior high school). As for NNES-4's speech, the speaker emphasized the verb "was" in this simple sentence. But it was really hard for listeners to grasp the implied meaning of using this marked tonicity here. Thus, the improper location of the information focus possibly increased the understanding difficulty of listeners.

Based on the tables and figures listed above, it could be concluded that Chinese EFL learners were able to use the marked tonicity to emphasize the information focus within one utterance. However, when speaking a more complex or long sentence, it was more possible for NNES to use marked tonicity excessively. Moreover, they had some improper use of marked tonicity because of the higher proportion of the use of function words. 


\subsection{TONE OF NATIVE ENGLISH SPEAKERS AND CHINESE EFL LEARNERS}

Based on Halliday's intonation systems, there are five simple tones (T1, T2, T3, T4, and T5) and two compound tones (T13 and T53). The frequency of each tone was counted and converted into a percentage for the comparison. Figure 6 shows the frequency of different tones that speakers used in simple sentences, and Figure 7 shows that in complex sentences.

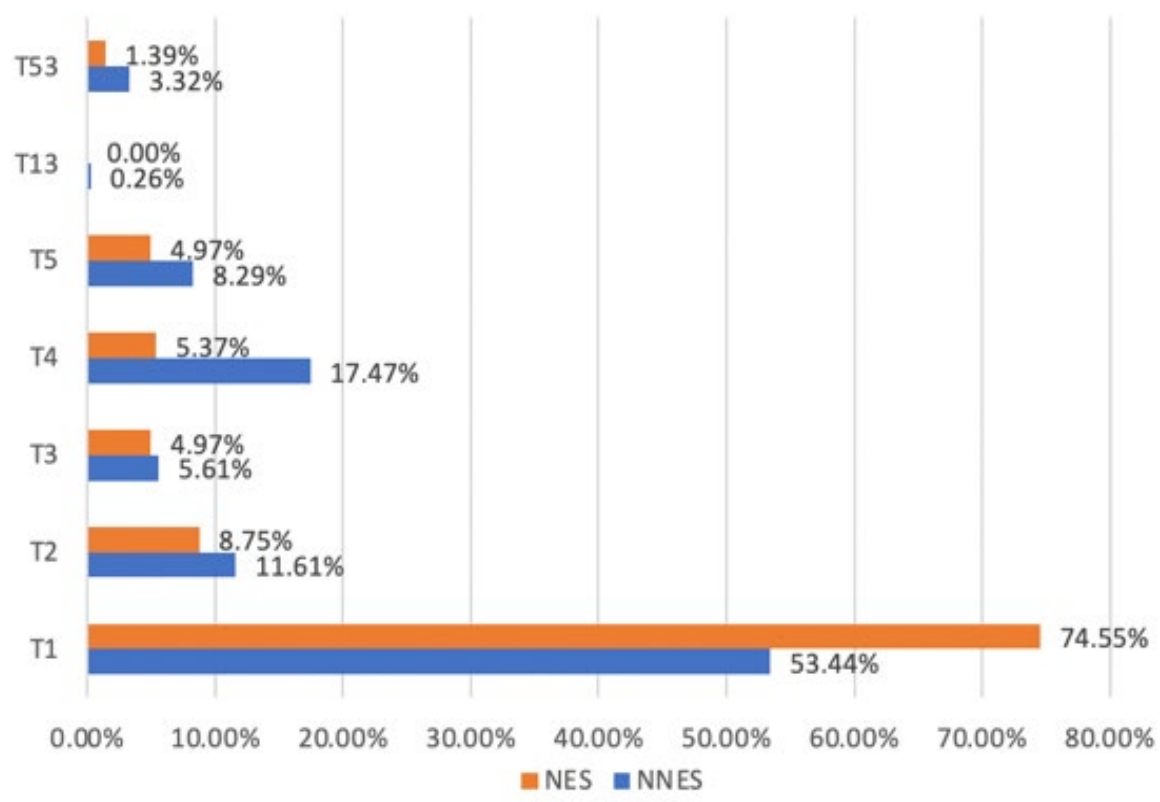

Figure 6. Comparison of tones that were used in simple sentences

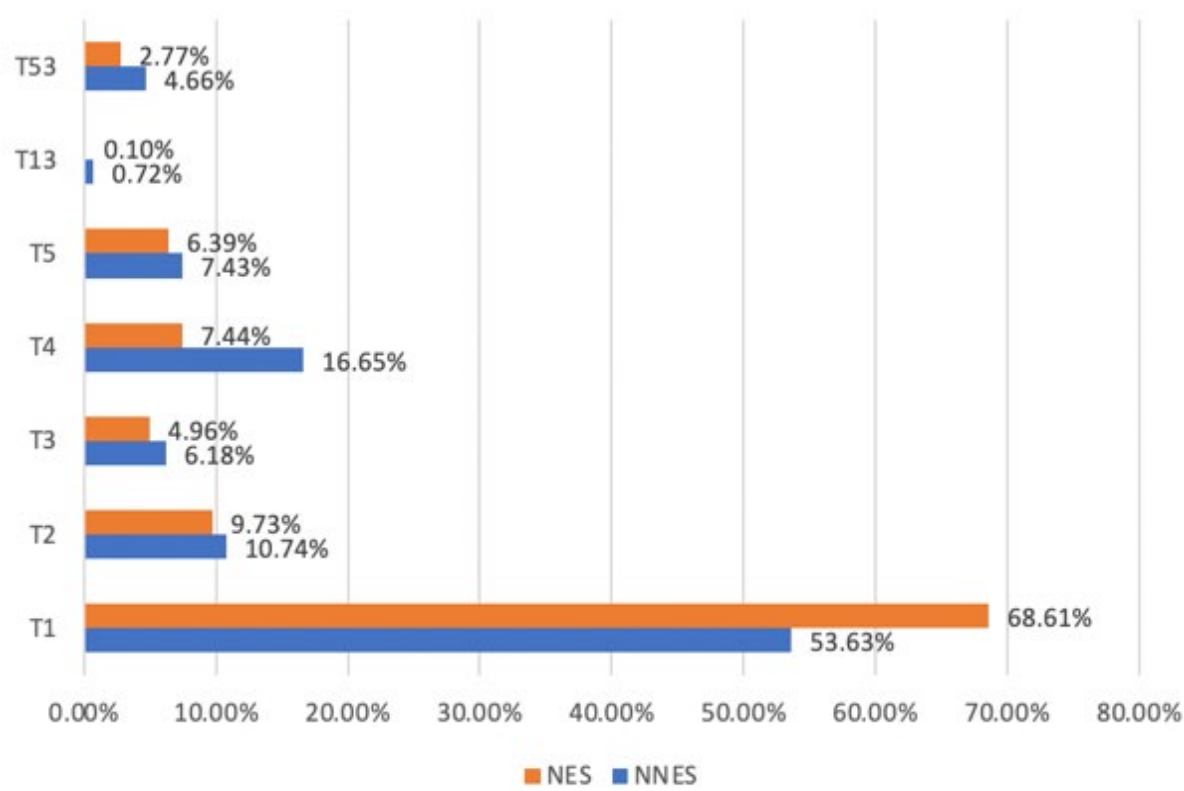

Figure 7: Comparison of different tones that were used in complex sentences

Based on Figure 6 and Figure 7, the proportion of the use of T1 was high than 50\% no matter in simple or complex sentences. Therefore, both Chinese EFL learners and native English speakers tended to use T1 in their speeches than any other tones. Besides, both of these two groups of speakers (NNES $=0.26 \%$; NES $=0.00 \%$ ) used T13 much less than other tones. Additionally, T2 and T4 were the most regularly used tones except for rise, although there was a difference of the employment of T2 and T4 between NNES (T2=11.61\%; T4=17.47\%) and NES 
A Comparative Study of Intonation Characteristics of Speeches by Chinese Efl Learners and Native Speakers

(T2=8.75\%; T4=5.37\%). But there still was the difference of using T1 between NES and NNES. NES (simple=74.55\%; complex $=68.61 \%$ ) used T1 more frequently than NNES (simple=53.44\%; complex=53.63\%) when delivering speeches in the two types of sentence structures.

Example:

5) // 1 It / is / a / way / for / you / to * understand / the / importance // 1 of */ sportsmanship // (NES-1)

6) // 1 From */strangeness *// 1 misunderstanding //1 to */cross / cultural / resonance // 1 it / takes / three $* /$ generations // (NNES-1)

Two examples mentioned here present the different employment of tones that English native speakers and Chinese students used in their speeches. The meaning of T1 proposed by Halliday (1967) was that it could represent "give + information". In Example 5), NES-1 used the falling tone (T1) to directly state his point of view, making it clear and concrete for audiences to understand the speaker's logic and purpose. As for Example 6), the speaker used only the falling tones when dividing the whole sentence into four separate tone groups. However, here the adjacent sentences should have some implied logical meaning, that // it takes three generations // was the independent information. Thus, a more appropriate use of tones here should be $/ / 4 / / 1 / /$.

A relatively similar use of most tones demonstrated that Chinese EFL learners could express their attitude or implied some relations between sentences with the help of different tones they used. However, the distinctive proportion of T1 in simple and complex sentences indicated that Chinese students might have a more changeable tones when delivering the speech. Moreover, there was some inappropriate use the distinctive tones in Chinese students' speeches.

\section{CONCLUSIONS AND RECOMMENDATIONS}

Based on Halliday's intonation systems, the present study investigated the intonation features of speeches delivered by Chinese EFL learners and English native speakers. On account of the comparison between the two groups of speakers, Chinese students were able to use tonality segmentation and marked tonicity to make their speeches more understandable. However, the excessive use of tone groups would increase the information units and led to the burden of listeners' comprehension. Besides, improper use of marked tonicity, like putting the marked tonicity on function words, might move the information focus to inappropriate location. Moreover, Chinese students had the awareness to use distinctive tones when delivering speeches. But sometimes, quite changeable tones were not useful for Chinese EFL learners to express their attitude or the relations between two adjacent utterances. Regarding the teaching of intonation, teachers and students could pay attention to these three aspects. Firstly, students need to have a more thorough understanding of information units and try to put the boundary tone at the right place. Secondly, it is necessary for EFL learners to reduce mistakes that put marked tonicity on meaningless function words. Thirdly, when using distinctive tones, students should not make their tones quite changeable.

\section{SOURCES OF FUNDING}

This research received no specific grant from any funding agency in the public, commercial, or not-for-profit sectors.

\section{CONFLICT OF INTEREST}

The author have declared that no competing interests exist.

\section{ACKNOWLEDGMENT}

This paper was sponsored by the Seed Foundation of Innovation and Creation for Graduate Students in Northwestern Polytechnical University CX 2020033. 


\section{REFERENCES}

[1] Zhu, W. (2012). Application of "input hypothesis" theory in teaching Chinese as a foreign language. Hubei social science (06), 139-142.

[2] Allen,V. (1971.) Teaching intonation, from theory to practice. TESOL Quarterly, (4):73-91.

[3] Cruttenden, (2002). A. Intonation. Cambridge: Cambridge University Press.

[4] Crystal, D. (1969). Prosodic Systems and Intonation in English. Cambridge Studies in Linguistics. Cambridge University Press.

[5] Fang, Z., Xin, C., Lu, H., Yang, S., \& Yang, Y. (2020). Research on Vocal Emotion Production of Preschool Children with Cochlear Implants and Normal Hearing Children. Chinese Scientific Journal of Hearing and Speech Rehabilitation,18(5):402-404.

[6] Halliday, M. A. K. (1967). Intonation and Grammar in British English. Berlin: Mouton.

[7] Halliday, M. A. K. \& Greaves. (2008) W. S., Intonation in the Grammar of English. London: Equinox.

[8] Haoxin, Y. (2020). A Study on the Effectiveness of Speech Visualization Technology in English Intonation Acquisition. Heilongjiang Education (Theory \& Practice) (7):89-90.

[9] $\mathrm{Hu}, \mathrm{C}$. (2009) On English Intonational Studies in the 20th Century. Journal of PLA University of Foreign Languages,32(03):13-20.

[10] Hua, C. (2008). On Chinese EFL Learner's English Intonation Pattern. Shanghai: Shanghai Foreign Language Education Press.

[11] Hua, C ., \& Ran, R. (2015). A Study on the Phonological Structure of Chinese English. Beijing: Foreign Language Teaching and Research Press.

[12] Honnet, P.E., Gerazov, B., Gjoreski, A. \& Garner, P.N. (2008). Intonation modelling using a muscle model and perceptually weighted matching pursuit.

[13] Jianfen, C. (2002). The relationship between Chinese tone and intonation. Studies of Chinese Language, 288:195.

[14] Ladd, D. R. (1996) Intonational Phonology. Cambridge: Cambridge University Press.

[15] Tench, P. (1996). The Intonation Systems of English. London: Cassell.

[16] O'Grady, G. (2002). Intonation and exchange: A dynamic and metafunction view. Lingua.

[17] Steffman, J. (2019) Intonational structure mediates speech rate normalization in the perception of segmental categories. Journal of Phonetics, 74.

[18] Xiuhua, H., \& Lei, Z. (2019). A Comparative Study of Perception of Speech Intonation between Hearing Impaired Children and Normal-hearing Children Aged 4 6 years. Journal of Audiology and Speech Pathology,28(2):138-141. DOI:10.3969/j.issn.1006-7299.2020.02.005. 